\title{
HYDROXYCARBOXYLIC ACIDS IN CHIRAL RECOGNITION: MODELING THE AMINE - HYDROXYCARBOXYLIC ACID INTERACTIONS*
}

\author{
MARCIN HOFFMANN', URSZULA RYCHLEWSKA ${ }^{2}$, AND JACEK RYCHLEWSKI] ${ }^{1,3}$ \\ ${ }^{\prime}$ Quantum Chemistry Group, Faculty of Chemistry, Adam Mickiewicz University \\ Grunwaldzka 6, 60-780 Poznań, Poland \\ ${ }^{2}$ Department of Crystallography, Faculty of Chemistry, Adam Mickiewicz University \\ Grunwaldzka 6, 60-780 Poznań, Poland \\ ${ }^{3}$ Institute of Bioorganic Chemistry, Polish Academy of Sciences \\ Wieniawskiego 17/19, 61-713 Poznań, Poland \\ hoffmann@man.poznan.pl_urszular@amii.edu.pl
}

(Rec. 27 November 2003)

\begin{abstract}
Crystal structures of diastereomeric salts of tartaric acid and 1,2-trans-diaminocyclohexane stimulated our interest in elucidating the mode of mutual interactions between the acid and the amine. For this purpose quantum mechanical methods were used to expound various modes of intermolecular recognition in vacuo, and the search through Cambridge Structural Database (CSD) was performed in order to characterize various hydrogen bonded ring motifs formed in crystals between the two components. The obtained results agree very well with the experimental observations, that the homochiral association of molecules is energetically favored over the heterochiral one. Mutual interactions between hydroxyacids and amines have been investigated using following simpler systems: glycolic acid, ammonia and methylamine in their neutral and ionic forms. Ammonia and amines tend to act as hydrogen bond acceptors from the carboxylic $\mathrm{OH}$ group in vacuo, which corresponds to the formation of salts in polar media. The cyclic hydrogen bond motif in which neighboring oxygen atoms are joined by the amine buckle is stable only in the system containing $\alpha$-hydroxyacetic acid and the ammonium cation.
\end{abstract}

\section{INTRODUCTION}

Systematic studies of the modes of packing in crystals of simple tartaric acid derivatives (esters, amides) has lead us to a discovery of several supramolecular motifs that are formed between complementary hydrogen bonding functional groups by utilizing multiple point hydrogen bond interactions [1]. Stability of various ring motifs obtained in such a way has been investigated in the gas phase and in solution by computational methods and compared with analogous patterns observed in crystals $[2,3]$. The persistence, in crystal structures, of some of these supramolecular motifs indicates that they might be substantial in molecular, and probably chiral, recognition and thus may play a significant role in crystal engineering and in designing new resolving agents, as well as chiral auxiliaries in the asymmetric syntheses.

\footnotetext{
* Dedicated to the memory of Professor Jacek Rychlewski
} 
Therefore the exciting task of modeling such interactions by the means of theoretical calculations have been undertaken. The main goal of the present study was to investigate the mode of hydrogen bond interactions between tartaric acid and 1,2-trans-diaminocyclohexane and between several pairs of model molecules possessing on one hand $\alpha$-hydroxycarboxyland on the other hand amine functions. We also wanted to gain information on the possible role of antiparallel local dipoles in stabilizing the structures of these systems.

\section{COMPUTATIONAL METHODS}

We have utilized ONIOM approach [4-7] to optimize geometries of the interacting $(R, \mathrm{R})$-tartaric acid with $(R, \quad R)$-1,2-trans-cyclohexanediamine or $(S, \mathrm{~S})$-1,2-trans-cyclohexanediamine. Briefly, in the ONIOM approach one divides the system into several layers, each treated at a different level of theory. The results obtained this way are utilized in ONIOM extrapolation scheme to approximate the energy of the large "real" system calculated at the high level of theory, as graphically depicted in Scheme 1 for a two-layer system, such as utilized in the current study. That is the relative energy of the whole real system is extrapolated as the sum of the energy calculated for its central - smaller part at high level of theory and the energy of the peripheral part calculated at much cheaper (low) level of theory. To obtain the energy of the peripheral part of the system one must subtract the energy of the central part from the energy of the whole real system at low level of theory.

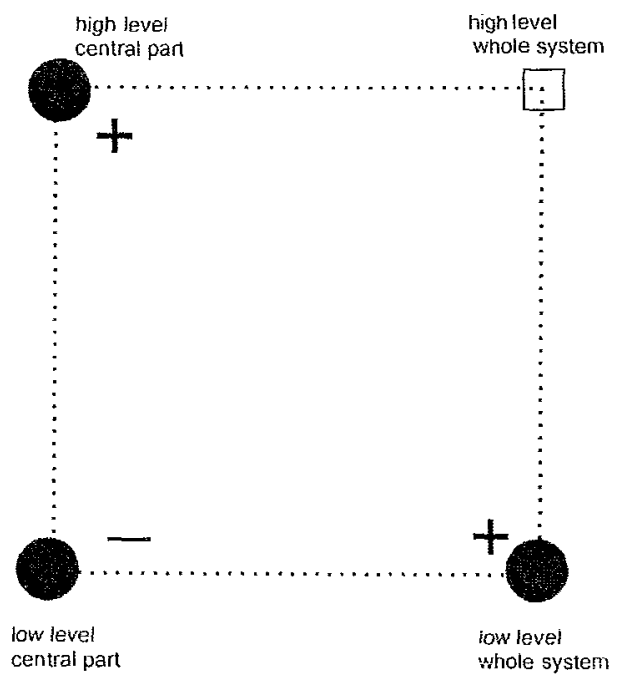

Scheme 1. Schematic illustration of the concept of the ONIOM method In ONIOM extrapolation scheme Energy of large system calculated at high level of theory Energy of the central part calculated at high level + Energy of the whole system calculated at low level - Energy of the central part calculated at low level. Thus computationally very expensive calculations for large system at high level of theory are avoided. Instead, cheaper calculations for (i) large system at low level, (ii) small system at high level, (iii) small system at low level are carried out

In this study density functional theory i.e. B3LYP/6-31+G(d) method was used as the high level one, while the low level calculations were performed using the spin-restricted HartreeFock method with 6-31G basis set. The central part of the system treated at high level of 
theory encompassed almost all of the system: whole tartrate anion and 1,2-ehtanediamine, so only the remaining four $\mathrm{CH}_{2}$ groups of 1,2-trans-cyclohexanediamine molecule were considered to be a peripheral part and were treated at low level. Even this allowed for a significant reduction of computational time during geometry optimization.

Having optimized the geometries of the interacting molecules we carried out single point calculations for the whole systems of homochiral and heterochiral salts at B3LYP/6-31+G(d) level, as well as for their anionic and cationic parts. In the latter we also tried to make up for the basis set superposition error using the usual counterpoise correction.

In the case of the model systems of glycolic acid and ammonia or methylamine we performed geometry optimization at B $3 \mathrm{LYP} / 6-31+\mathrm{g}(\mathrm{d})$ level. All calculations were performed with the use of Gaussian03 version [8] in Poznań Supercomputing and Networking Center.

\section{RESULTS AND DISCUSSION}

\subsection{Modeling the mode of cation - anion association in a pair of diastereomeric salts of tartaric acid and 1,2-diaminocyclohexane}

Classical resolution based on different solubility of diastereomeric salt pairs has become an essential method for the preparation of the vast majority of chiral organic compounds. One of the most effective resolving agents is chiral tartaric acid and its derivatives [9]. When applied to a crude mixture of 1,2-trans-diaminocyclohexane isomers, $(R, R)$-tartaric acid interacts more strongly with $(R, R)$-1,2-trans-diaminocyclohexane giving the least soluble $1: 1$ homochiral salt [10]. The crystal structure of this salt has been determined by Hanessian and co-workers [11], The heterochiral associate containing $(S, S)$-1,2-trans-diaminocyclohexane with $(R, R)$-tartaric acid comes out from the solution after introduction of an excess of $(R, R)$-tartaric acid leading to the 1:2 salt (see Scheme 2). This crystal structure has recently been determined in our laboratory [12]. By comparing the crystal structures formed by diastereomeric salts of trans-1,2-diaminocyclohexane with chiral tartaric acid it is possible to demonstrate that the mode of association of the homochiral salt differs substantially from the mode of association of the heterochiral one. This difference is already seen on the level of two interacting molecules (Fig. 1) and continues to build up in the whole crystal.

In the homochiral 1:1 salt the cation/anion assembly is realized by simultaneous binding of two ammonium groups from the cation with two hydroxyl groups of the anion (Fig. la). This leads to the formation of a scissors-shaped hydrogen bonding motif consisting of a dual hydrogen bond between the vicinal hydroxyl and ammonium groups. The mode of binding by means of these hydrogen bonds resembles the well known amine/hydroxyl motifs intensively investigated by several authors [13-17]. However, in majority of cases, the studied amine/hydroxyl clusters contained uncharged constituents and were free from other hydrogen bonding competitors, while in the homochiral 1:1 salt of tartaric acid and 1,2-trans-diamino- 
cyclohexane the $\mathrm{NH} \ldots \mathrm{OH}$ hydrogen bonds are formed between the charged species and despite the presence of competing carboxylate groups. Interestingly, such a dual hydrogen bond formation between tartrate and cyclohexanediammonium cation seems possible only when the mutual arrangement of ammonium groups in the cation has the same helicity as the mutual orientation of hydroxyl groups in the anion, because in the crystal structure of the heterochiral salt, such a match of the two partners is not observed. Instead, the $(S, S)$-diaminocyclohexane cations place themselves in the vicinity of $\alpha$-hydroxycarboxylate and $\alpha$-hydroxycarbonyl groups, situated at both ends of the (R, R)-hydrogentartrate anion (Fig. 1b), so the anion interacts with two different cationic species. Both cations form similar hydrogen bonds with the anion, i.e. mediate in liking two neighboring oxygen atoms from the $\alpha$-hydroxycarboxylate moiety by means of three-center hydrogen bonds. The resulting $\mathrm{R}_{1}{ }^{2}(5)$ motifs (for description of the graph set notation see Bernstein et al. [18]) has been observed in $(R, \mathrm{R})$-tartaric acid [19] and ( R, R)-N-methyltartramic acid [20] where, instead of ammonium hydrogen, the role of mediator was played by the hydroxyl and water hydrogens, respectively. What seems characteristic for the ion pairing observed in the heterochiral 1:2 salt is that the mutual cation/anion interactions are being limited to only half of the actual hydrogentartate molecule and thus the tartartrate chirality is not 'seen' by the amine. One might say that in this case the chirality of hydrogentartartrate influences only mutual orientation of the two interacting diammmonium cations.

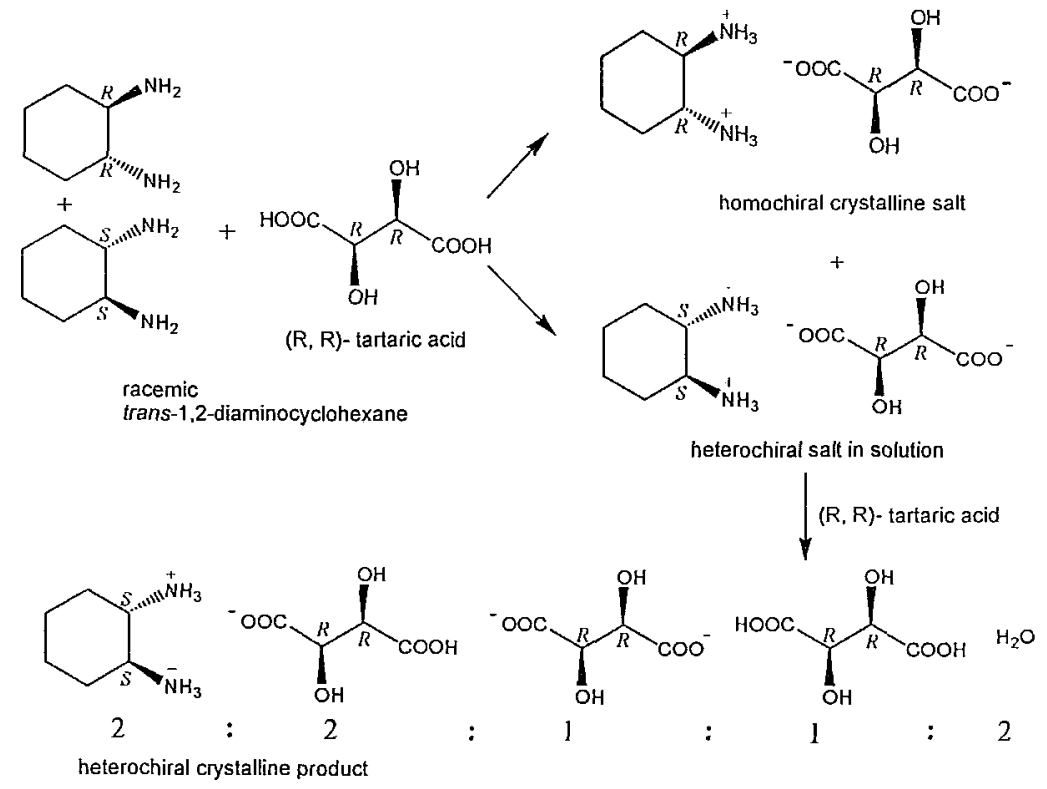

Scheme 2. Schematic presentation of the process of the resolution of the crude mixture of the isomers of trans-1,2-diaminocyclohexane through the process of crystallization of diastereomeric salts with the chiral tartaric acid [10] 
The heterochiral 1:1 salt of diaminocyclohexane and tartaric acid has also been investigated by $\mathrm{X}$-ray analysis [11]. In general, the mode of mutual interactions between the two ions is very similar to the one observed in the 1:2 heterochiral salt (compare Figs. $1 \mathrm{~b}$ and $1 \mathrm{c}$ ) except that in the $1: 1$ salt we observe, in addition to the $R_{1}{ }^{2}(5)$ motif, a direct interaction of one of the ammonium protons with two oxygen atoms belonging to the same carboxylate moiety, resulting in the formation of the three-center hydrogen bond designated in the graph set notation as $R_{1}^{2}(4)$.

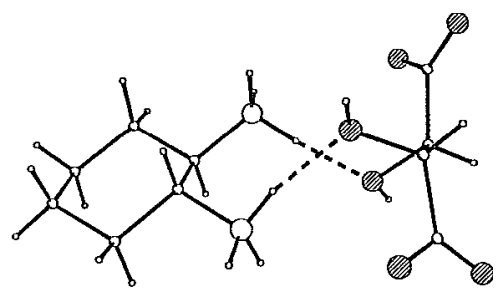

a

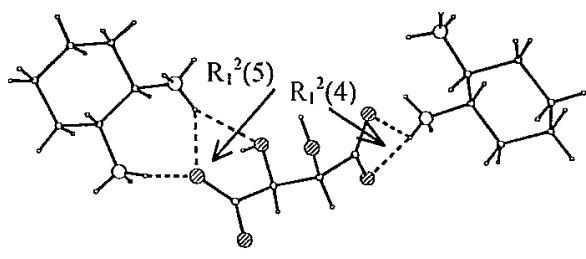

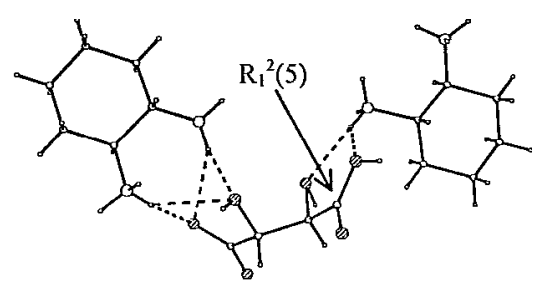

$\mathrm{b}$

Fig. 1. Illustration of The mode of mutual hydrogen bond interactions between the cation/anion pairs in the diastereomeric salts of trans1,2-diaminocyclohexane with chiral tartaric acid as observed in the crystal structures of a) homochiral 1:1 salt [11], (b) heterochiral 1:2 salt [12] and (c) heterochiral 1:1 salt [11]

$\mathrm{C}$

Table 1. Relative energies in $\mathrm{kcal} / \mathrm{mol}$ of the interacting salts: homochiral $[(R, R)$-tartaric acid and $(R, R)$-1,2-trans-cyclohexanediamine $]$ and heterochiral $[(R, R)$-tartaric acid and $(S, S)$-1,2-trans-cyclohexanediamine]. Results for the acid and the amine are counterpoise corrected (CP) or not. The data for the acid and the amine show the relative deformation energies. The interaction energy is calculated as the difference between binding energy and deformation energy

\begin{tabular}{lcc}
\hline \multicolumn{1}{c}{ Relative energies } & Homochiral & Heterochiral \\
\hline Salt: binding energy & 0.0 & 2.5 \\
Amine: deformation energy & 4.6 & 0.0 \\
Amine: deformation energy $^{C P}$ & 4.5 & 0.0 \\
Acid: deformation energy $^{C P}$ & 0.0 & 1.3 \\
Acid: deformation energy $^{C P}$ & 0.0 & 1.3 \\
Salt: interaction energy & 0.0 & 5.8 \\
Salt: interaction energy $^{C P}$ & 0.0 & 5.7 \\
\hline
\end{tabular}

Theoretical calculations, carried out for the divalent cation - anion systems (Table 1) indicate that the homochiral clusters formed by pairs of molecules that have identical descriptors with respect to the orientation of their $\mathrm{OH}$ and $\mathrm{NH}_{3}{ }^{+}$groups $(R, R$ in this case) are energetically favored (see Fig. 2). The calculated interaction energy, even when counterpoise 
corrected, is of almost $6 \mathrm{kcal} / \mathrm{mol}$ greater for the homochiral salt formed by $(R, R)$-1,2-transcyclohexanediamine and $(R, R)$ tartaric acid then for the heterochiral salt formed by $(\mathrm{S}, \mathrm{S})$-1,2-trans-cyclohexanediamine and $(R, R)$ tartaric acid, clearly indicating that homochiral recognition is preferred.
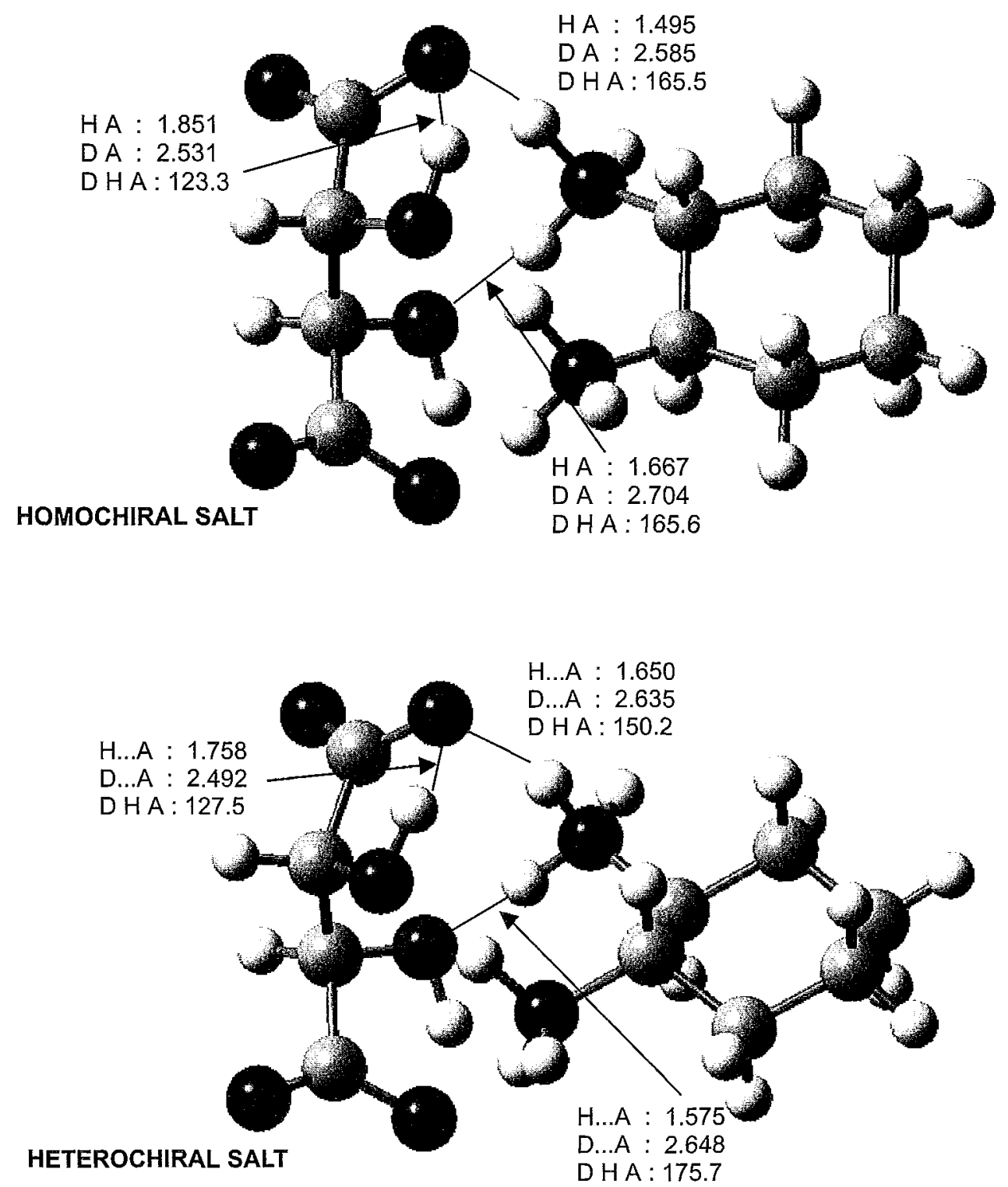

Fig. 2. Mutual hydrogen bond interactions in two diastereomeric pairs of divalent ions: trans-1,2cyclohexanediammonium cation and $(R, \mathrm{R})$-tartarate: homo- and heterochiral, as modeled by quantum mechanical calculations. HA and DA distances in $\AA$. DHA angle in o 
As shown in Table 1 the relative energy of the interacting species - the binding energy - is of $2.5 \mathrm{kcal} / \mathrm{mol}$ lower in the homochiral than in the heterochiral system. This difference results from greater deformation of diamonium cation in homochiral system $(4.5 \mathrm{kcal} / \mathrm{mol})$, not fully balanced by the lower deformation of tartaric acid $(1.3 \mathrm{kcal} / \mathrm{mol})$.

Higher susceptibility to deformation of diamines (attached to a rigid cyclohexane) than tartrates, has been interpreted by us as another indication of the observed preference of chiral tartaric acid molecule (regardless of its ionization state) to adopt only one type of conformation (i.e. the extended carbon chain form) despite its capacity for considerable conformational freedom. Statistical analysis of data deposited in the CSD [21] reveals that among the chiral tartaric acid derivatives and salts possessing antiperiplanar conformation of the four atom carbon chain, mutual disposition of the $\mathrm{CH}$ and $\mathrm{CO}$ dipoles situated in the $\beta$-position with respect to each other is very consistent (Fig. 3). The two dipoles are inclined with respect to each other at roughly 60 or $180^{\circ}$, depending on which of the two carboxylate CO bonds has been taken into account. In other words, the $\beta \mathrm{CH}$ bond is always placed in an antiparallel orientation with respect to one of the carboxylate $\mathrm{CO}$ bonds. We interpret this finding as an indication of the existence of dipolar $\mathrm{CO} / \beta \mathrm{CH}$ interactions. Since there are two such $\mathrm{CO} / \mathrm{CH}$ bond arrangements in each tartrate molecule, the stabilizing effect of these dipolar interactions might be substantial. Distribution of the angular values describing the mutual disposition of the $\mathrm{CO}$ and $\beta \mathrm{CH}$ dipoles in 343 tartrates (686 fragments) deposited in the CSD is shown in Figs. $3 \mathrm{a}$ and $\mathrm{b}$. Concentration of all values in the region of 60 and $180^{\circ}$ is a good illustration of consistency of data and thus indicates the importance of such interactions for the conformational stability and preference. The effect is also observed in the calculated minimum energy structures. The angles between the interacting dipoles in the two theoretically
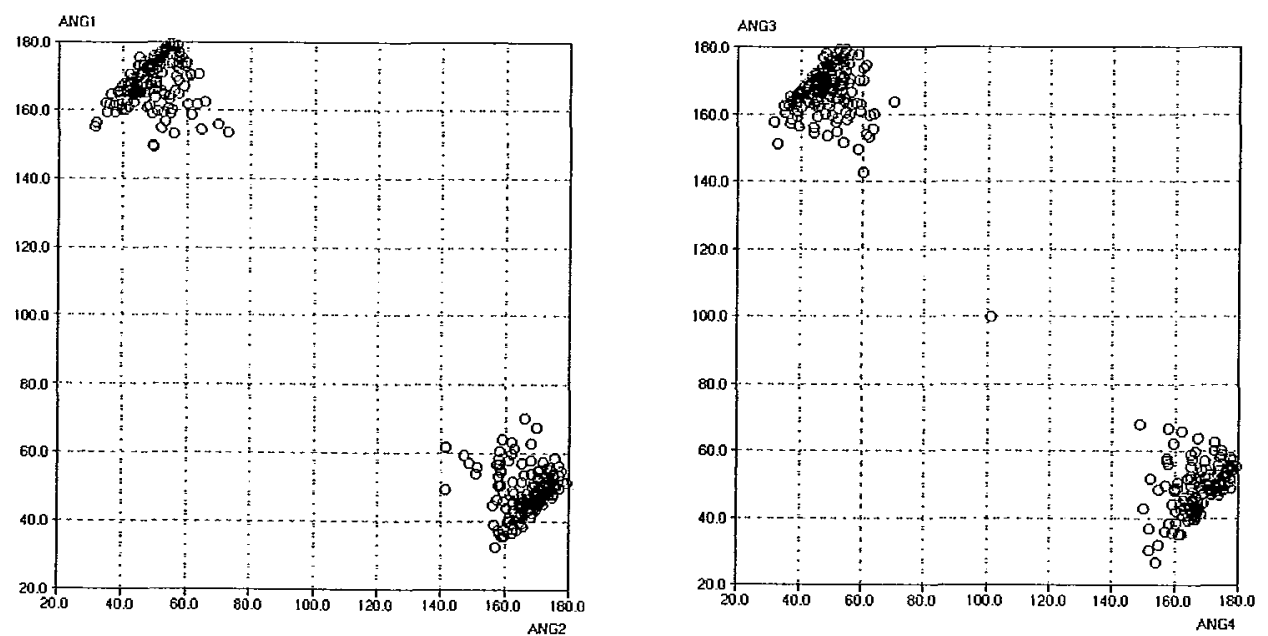

Fig. 3. Scatter plots showing the distribution of angles formed by $\mathrm{CO} / \beta \mathrm{CH}$ dipoles in 343 tartrates 
obtained tartrate anions are in the range $150.1^{\circ}$ for the heterochiral salt where tartarate is more distorted (for example C-C-C-C torsion angle equals $158.0^{\circ}$ ) to $162.7^{\circ}$ for the homochiral salt where C-C-C-C torsion angle of the tartrate equals $171.1^{\circ}$.

The mode of hydrogen-bond interactions that follows from theoretical in vacuo calculations is nearly identical for the homochiral and heterochiral salts. According to quantum chemical calculations the preferred interaction between cyclohexanediammonium cation and tartrate anion is such that each of the two ammonium groups joins two oxygen atoms belonging to the $\beta$-hydroxycarboxylate moiety using a pair of NH...0 hydrogen bonds. For heterochiral salt, such a motif is energetically disfavored by $6 \mathrm{kcal} / \mathrm{mol}$ comparing to homochiral salt. Thus, as could be expected, it differs very much from patterns observed in the crystal structure, where each half of the acid interacts with 'its own' diamine. Clearly for the heterochiral salt the energetically disfavored mode of interaction observed in isolated molecules must compete with other motifs of association that involve many molecules. Because its relative energy with respect to homochiral salt is of $6 \mathrm{kcal} / \mathrm{mol}$ higher, motifs that involve many molecules must and do win. In contrast, in the case of homochiral salt the situation is different. The interaction mode between the acid and the amine is definitely more favored, so the amine molecule in vacuo may be distorted by over $4 \mathrm{kcal} / \mathrm{mol} \mathrm{more} \mathrm{in}$ homochiral than in heterochiral salt, as the protonated amine groups bearing positive charge are strongly attracted by negative charges of carboxylate groups of the acid, causing a significant distortion in the amine molecule. In crystal structure these positive charges of the protonated amine groups are balanced by the neighboring carboxylates of the other tartaric acid molecules, which are forming infinite ribbons amine - acid - amine - acid - etc, as observed in the crystals of the homochiral salt. Therefore in the crystal structure much of the deformation of the individual amine molecules may be avoided.

The observed difference in the preferred mode of ion pairing in the solid state and in the isolated state is not unexpected owing to the fact that the most energetically preferred are those arrangements which tend to exploit all available hydrogen-bonding sites. Isolated molecules can not find other neighbors, while in the condensed media there exists a possibility of further intermolecular extension of the primary hydrogen-bond motifs. The discussed difference in the mode of ion pairing in the two states of matter can also be interpreted in favor of one of the possible scenarios of the process of chiral resolution. One of the possibilities is such that homochiral molecules of diamine and tartaric acid interact through hydrogen bonds to produce the starting unit, the diamine/diol cluster, followed by further assembly of such supramolecular units. However, this scenario seems rather unlikely for at least two reasons. Firstly, such supramolecular motif is not the most energetically preferred in the isolated state. Secondly, it seems very unlikely that in the competing situation the $\mathrm{NH}$... OH hydrogen bond will be preferred over the NH...carboxylate bonds (vide infra). The other scenario is such that the preorganized arrangement of one of the components is present, as for example the well known chains of tartaric acid molecules connected in a head to tail mode by carboxyl/carboxylate hydrogen bonds. In the process of diastereomeric salt formation 
the chain accommodates the other partner (e.g. diamine) in energetically most favorable terms. Of course, in between these two considered extreme cases there might be other more complex and more likely possibilities which are rather difficult to predict owing to the spontaneity and complexity of the process of crystallization of diastereomeric salts. At this stage we have considered it worth to examine the preferred modes of association in the systems containing amine and $\alpha$-hydroxycarboxylic fragments.

\subsection{Modeling the favored mode of hydrogen bond interactions between}

the $\alpha$-hydroxycarboxyl (or $\alpha$-hydroxycarboxylate) residues

and amine (or ammonium) groups

Dual association with the hydrogen atom from ammonium cation as a mediator in joining together by hydrogen bonds two oxygen atoms of the $\alpha$-hydroxycarboxylate fragment, observed in the crystal structure of the heterochiral salt of (S, S)-diaminocyclohexane and $(\mathrm{R}, \mathrm{R})$-tartaric acid, is not stable in the isolated state. In all systems containing $\alpha$-hydroxyacetate as one of the interacting sites the energetically preferred interaction involves solely the carboxylate group, regardless whether it interacts with ammonia or amine molecules.

\subsubsection{Glycolic acid and ammonia}

Table 2 presents relative binding energies, relative deformation energies, as well as interaction energies for the stable minima of the interacting glycolic acid and ammonia. In the lowest energy, the $\mathbf{Z}$ structure, ammonia associates with glycolic acid in such a way that it closes six membered ring with carboxylic $\mathrm{OH}$ group acting as hydrogen bond donor and nitrogen as acceptor, as well as NH being a donor and carbonyl oxygen an acceptor (see Fig. 4).

Table 2. Relative energies (in $\mathrm{kcal} / \mathrm{mol}$ ) of the interacting molecules of glycolic acid and ammonia in vacuo: binding energy, deformation energy of the acid and ammonia, as well as interaction energy of the acid and ammonia for various structures of the interacting molecules

\begin{tabular}{lccccc}
\hline \multirow{2}{*}{ Structure } & $\begin{array}{c}\text { Relative } \\
\text { Binding Energy }\end{array}$ & \multicolumn{2}{c}{ Relative Deformation Energy } & \multicolumn{2}{c}{ Interaction Energy } \\
\cline { 2 - 6 } & Complex & Acid & Ammonia & CP & \\
\hline Z & 0.0 & 0.0 & 0.0 & -13.1 & -14.8 \\
Ya & 2.0 & 2.7 & 0.0 & -13.8 & -15.5 \\
B & 5.0 & 0.8 & 0.0 & -9.2 & -10.7 \\
Za & 5.7 & 4.8 & 0.0 & -12.3 & -13.9 \\
Y & 6.0 & 4.9 & 0.0 & -12.0 & -13.7 \\
Al & 7.0 & 2.1 & 0.0 & -8.3 & -9.9 \\
D & 7.9 & 6.3 & 0.0 & -11.4 & -13.2 \\
X & 8.8 & 5.0 & 0.0 & -9.2 & -11.1 \\
Xa & 8.8 & 5.3 & 0.0 & -9.5 & -11.3 \\
A & 14.6 & 3.9 & 0.0 & -3.4 & -4.1 \\
\hline
\end{tabular}

${ }^{\mathrm{CP}}$ counterpoise corrected 

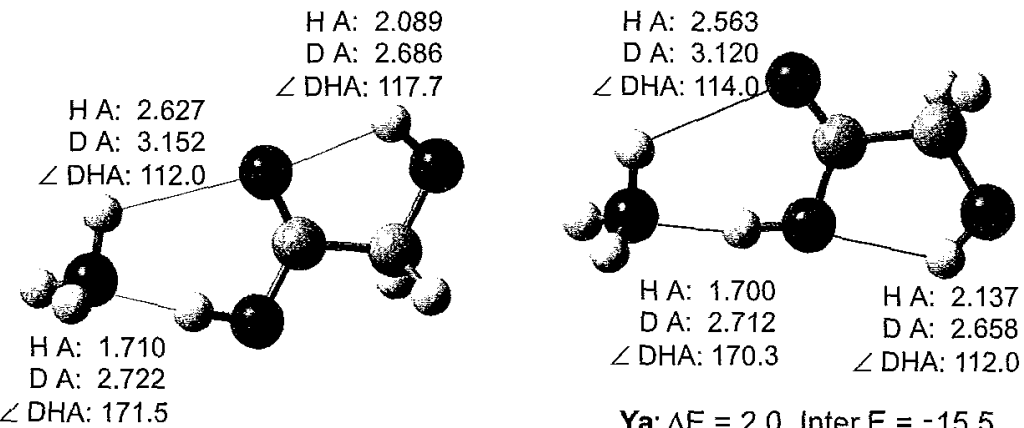

$Z \Delta E=0.0$ Inter. $E=-14.8$

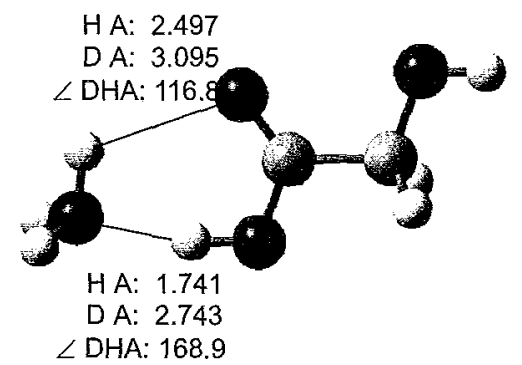

$\mathrm{Za}: \Delta \mathrm{E}=5.7$ Inter. $\mathrm{E}=-13.9$

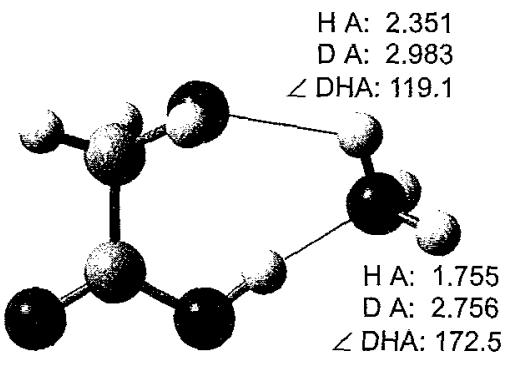

D. $\Delta \mathrm{E}=7.9$ Inter. $\mathrm{E}=-13.2$
A: 1853

D A: 2.839

$\angle \mathrm{DHA}: 173.6$

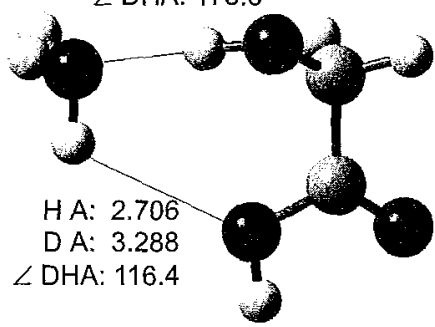

At $\Delta E=7.0$ Inter. $E=-8.3$

HA: 1.846

D A: 2.826

$\angle \mathrm{DHA}: 168.6$

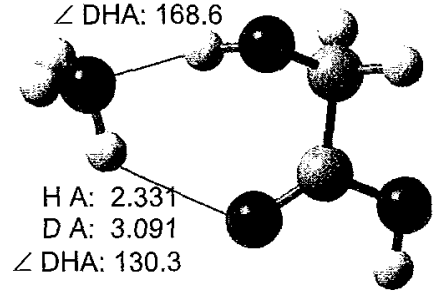

B. $\Delta E=5.0$ Inter. $E=-10.7$

Fig. 4. Selected structures of interacting glycolic acid with ammonia corresponding to local minimas of energy. Hydrogen bonding interactions characterized by hydrogen - acceptor (HA) and donor - acceptor (DA) distances (in $\AA$ ) as well, as an angle donor - hydrogen - acceptor ( $\angle$ DHA, degrees). Relative energy of the system $\Delta \mathrm{E}$ corresponds to the relative binding energy, while Inter. $E$ stands for interaction energy calculated without counterpoise correction, both values in $[\mathrm{kcal} / \mathrm{mol}]$ 
The glycolic acid molecule is then stabilized by intramolecular hydrogen bond between $\alpha$-OHand carbonyl oxygen. It is worth mentioning that a hydrogen bond in which $\mathrm{COOH}$ acts as donor and nitrogen as an acceptor is particularly strong - situation that in condensed more polar media is most likely to be substituted by ionic interactions between glycolate anion and $\mathrm{NH}_{4}{ }^{+}$cation. However, in our in vacuo calculations, such ionic systems had a strong tendency to converge to non-ionic species, which had significantly lower energy, then ionic ones. Interestingly the lowest energy the $\mathbf{Z}$ structure does not correspond to the one with the most favorable interaction energy - the Ya one. The Ya does not differ from the $\mathbf{Z}$ mode of interaction between the ammonia and the acid, however, within the glycolic acid part the intramolecular hydrogen bond with $\alpha-\mathrm{OH}$ as a donor leads to carboxylic $\mathrm{OH}$ (for Ya structure) instead of carbonyl oxygen (for $\mathbf{Z}$ ). Thus in the Ya structure the carboxylic $\mathrm{OH}$ group is both an acceptor and a donor, as the OH...OH...N motif is formed, which is of almost $1 \mathrm{kcal} / \mathrm{mol}$ more energetically favored then the motif observed in the $\mathbf{Z}$ structure. This is yet another convincing evidence of the energy gain due to cooperativity of hydrogen bonds. This energy is not sufficient, however, to overcome additional stabilization from the more (by $2 \mathrm{kcal} / \mathrm{mol}$ ) favored $\mathrm{OH} \ldots \mathrm{O}=\mathrm{C}$ hydrogen bond present in the $\mathbf{Z}$ structure.

\subsubsection{Glycolic acid and methylamine}

Table 3 presents relative binding energies, relative deformation energies, and interaction energies for the stable minima of the interacting glycolic acid and methylamine. Similar to

Table 3. Relative energies (in $\mathrm{kcal} / \mathrm{mol}$ ) of the interacting molecules of glycolic acid and methylamine in vacuo: binding energy, deformation energy of the acid and amine, as well as interaction energy of the acid and amine for various structures of the interacting molecules

\begin{tabular}{lccccc}
\hline \multirow{2}{*}{ Structure } & $\begin{array}{c}\text { Relative } \\
\text { Binding Energy }\end{array}$ & \multicolumn{2}{c}{ Relative Deformation Energy } & \multicolumn{2}{c}{ Interaction Energy } \\
\cline { 2 - 6 } & Complex & Acid & Ammonia & CP & \\
\hline Z & 0.0 & 0.0 & 0.1 & -14.8 & -16.2 \\
Ya & 2.0 & 2.5 & 0.1 & -15.4 & -16.8 \\
B & 5.3 & 0.0 & 0.0 & -9.7 & -10.9 \\
Za & 5.8 & 4.3 & 0.1 & -13.3 & -14.7 \\
Y & 6.1 & 4.4 & 0.1 & -13.1 & -14.5 \\
1A & 7.2 & 1.3 & 0.0 & -8.9 & -10.2 \\
1B & 7.4 & 1.2 & 0.0 & -8.8 & -10.1 \\
D1 & 8.0 & 5.9 & 0.1 & -12.6 & -14.1 \\
D2 & 8.0 & 5.7 & 0.1 & -12.4 & -14.0 \\
Ax & 8.7 & 4.8 & 0.0 & -10.8 & -12.3 \\
Ay & 8.8 & 5.0 & 0.0 & -10.9 & -12.4 \\
A1 & 15.4 & 3.0 & 0.0 & -3.2 & -3.7 \\
A2 & 15.5 & 3.0 & 0.0 & -3.1 & -3.6 \\
\hline
\end{tabular}

${ }^{\mathrm{CP}}$ counterpoise corrected 
HA: 2.084

D A: 2.683

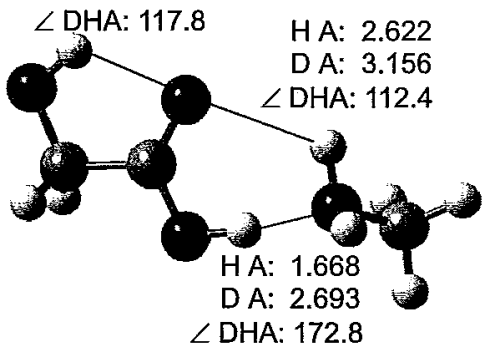

$Z: \Delta E=0.0$ Inter. $E=-16.2$
HA: 2.554

D A: 3.120

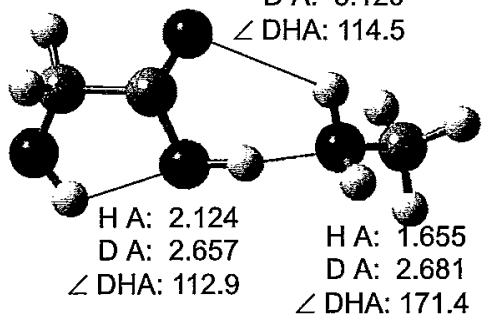

$\mathrm{Ya}: \Delta \mathrm{E}=2.0$ Inter. $\mathrm{E}=-16.8$

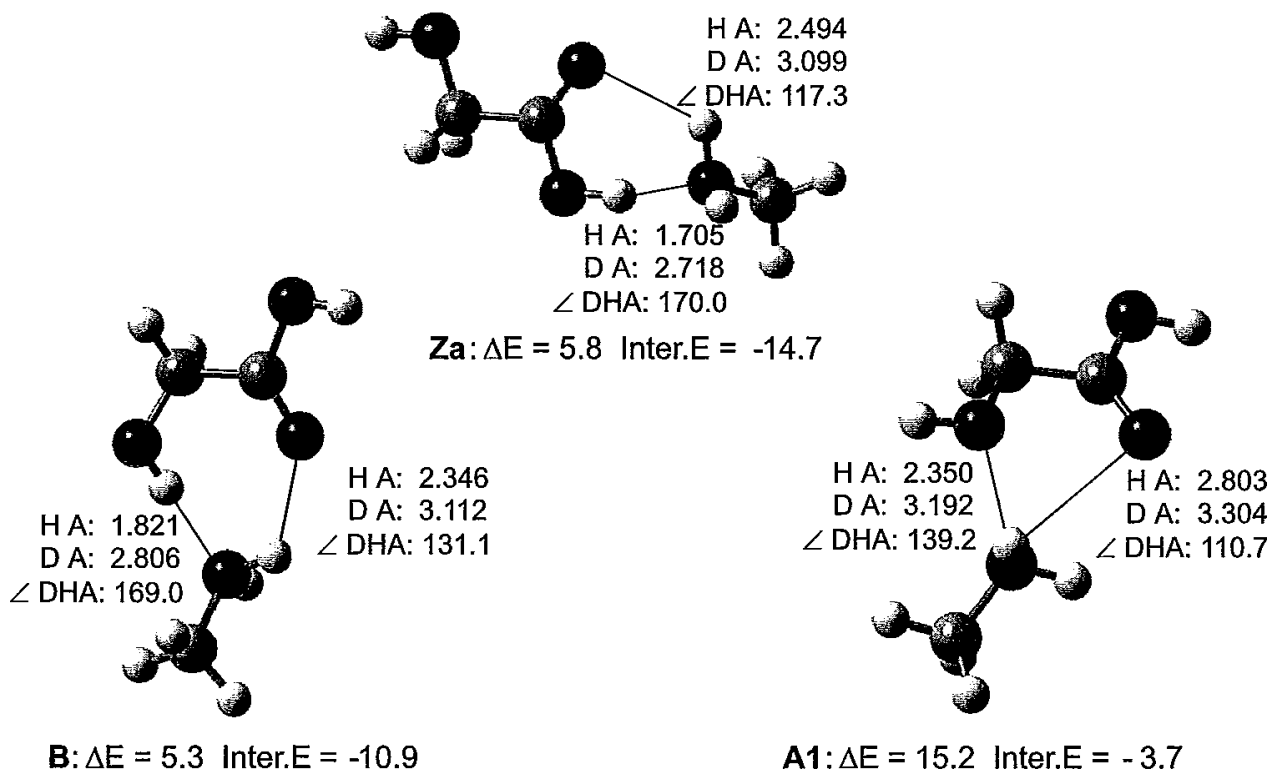

Fig. 5. Selected structures of interacting glycolic acid with methylamine corresponding to local minima of energy. Hydrogen bonding interactions characterized by hydrogen - acceptor (HA) and donor - acceptor (DA) distances (in $\AA$ ) as well as an angle donor - hydrogen - acceptor ( $\angle D H A$, degrees). Relative energy of the system $\Delta E$ corresponds to the relative binding energy, while Inter. $E$ stands for interaction energy calculated without counterpoise correction, both values in $[\mathrm{kcal} / \mathrm{mol}]$

a system of glycolic acid with ammonia, the lowest energy structure is the $\mathbf{Z}$ one. The amine nitrogen is an acceptor of a hydrogen bond from carboxylic $\mathrm{OH}$ and $\mathrm{NH}$ is a donor of a hydrogen bond with carbonyl oxygen being an acceptor (see Fig. 5). Within the acid molecule there is an intramolecular hydrogen bonding interaction closing five membered ring with $\alpha$-OH as a donor and carbonyl oxygen as an acceptor. Like for ammonia the structure with the strongest 
interaction is not the one of lowest energy $(\mathbf{Z})$, but the $\mathbf{Y a}$ one, which differs from the $\mathbf{Z}$ only by the rotation about $C s p^{3}-C s p^{2}$ bond of the acid.

It is worth mentioning that a hydrogen bond in which $\mathrm{COOH}$ acts as donor and amine nitrogen as an acceptor is particularly strong - situation that in condensed more polar media is most likely to be substituted by ionic interactions between glycolate anion and protonated amine.

\subsubsection{Glycolic acid and ammonium cation}

Relative energies of the complexes, deformation energies and interaction energies are presented in Table 4 for various modes of interaction between glycolic acid and ammonium cation. The lowest energy forms the $\mathbf{C}$, and $\mathbf{A}$ are very similar not only because of their energy difference of $0.5 \mathrm{kcal} / \mathrm{mol}$, but also due to similar mode of interaction, which differs from one another by relative distance of hydrogen bonds (see Fig. 6).

In the case of the lowest energy, the $\mathbf{C}$ structure, the strongest is the hydrogen bond joining $\mathrm{NH}$ and carbonyl oxygen (proton acceptor distance of $1.644 \AA$ ), while the secondary one is the interaction that joins $\mathrm{NH}$ and $\alpha-\mathrm{OH}$ via the same hydrogen (proton acceptor distance of $2.265 \AA$ ). The weakest is the interaction between $\mathrm{NH}$ and $\alpha-\mathrm{OH}$ via another hydrogen (proton acceptor distance of $2.547 \AA$ ). For the A structure the importance of the hydrogen bonds alters. The strongest is the bonding between $\mathrm{NH}$ and $\alpha-\mathrm{OH}$ ( $\mathrm{H} \mathrm{A}$ distance of $1.780 \AA$ ),

Table 4. Relative energies (in $\mathrm{kcal} / \mathrm{mol}$ ) of the interacting molecules of glycolic acid and ammonium cation in vacuo: binding energy, deformation energy of the acid and ammonium cation, as well as interaction energy of the acid and ammonium cation for various structures of the interacting molecules

\begin{tabular}{cccccc}
\hline \multirow{2}{*}{ Structure } & $\begin{array}{c}\text { Relative Binding } \\
\text { Energy }\end{array}$ & \multicolumn{2}{c}{ Relative Deformation Energy } & \multicolumn{2}{c}{ Interaction Energy } \\
\cline { 2 - 5 } & Complex & Acid & $\mathrm{NH}_{4}^{+}$ & $\mathrm{CP}$ & \\
\hline $\mathbf{C}$ & 0.0 & 1.8 & 0.4 & -34.8 & -35.5 \\
$\mathbf{A}$ & 0.5 & 1.6 & 0.5 & -34.2 & -35.0 \\
$\mathbf{D}$ & 0.9 & 0.0 & 0.6 & -32.6 & -33.1 \\
$\mathbf{A 1}$ & 9.0 & 1.5 & 0.0 & -24.9 & -25.9 \\
C1 & 9.2 & 1.6 & 0.1 & -25.1 & -25.9 \\
\hline
\end{tabular}

$\mathrm{CP}$ counterpoise corrected

the secondary is the bonding between $\mathrm{NH}$ and $0=\mathrm{C}$ via different hydrogen atom ( $\mathrm{H}$ A distance of $1.925 \AA$ ), while the weakest is the bonding $\mathrm{NH}$ and $0=\mathrm{C}$ via the same hydrogen atom as in the case of the strongest intermolecular interaction (H A distance of $2.612 \AA$ ). 


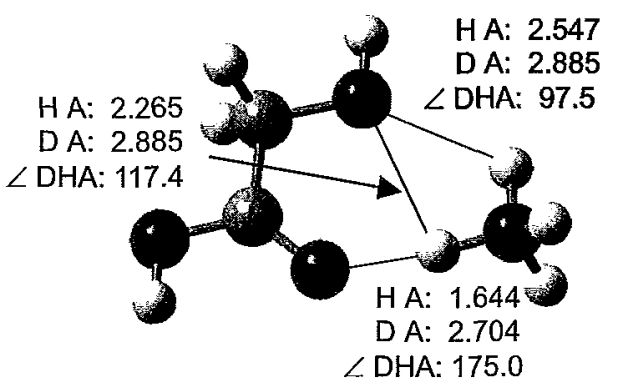

C: $\Delta \mathrm{E}=0.0$ Inter. $\mathrm{E}=\mathbf{- 3 5 . 5}$

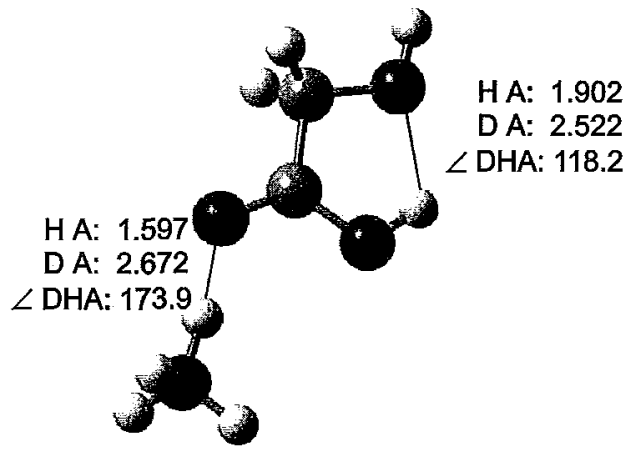

$\mathrm{D}: \Delta \mathrm{E}=0.9$ Inter. $\mathrm{E}=-33.1$

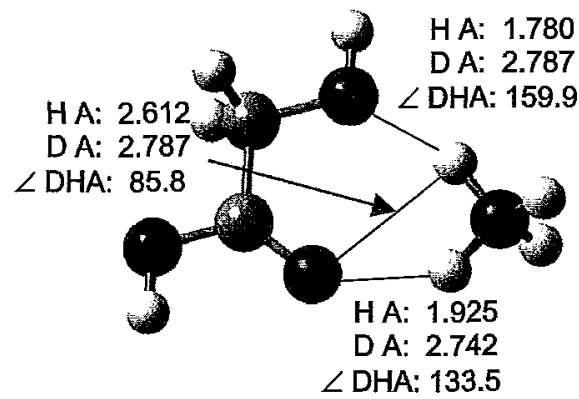

$\mathrm{A}: \Delta \mathrm{E}=0.5$ Inter. $\mathrm{E}=\mathbf{- 3 5 . 0}$

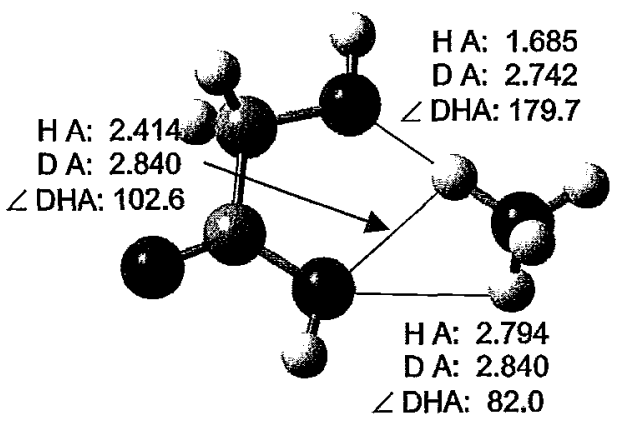

A1: $\Delta \mathrm{E}=9.0$ Inter. $\mathrm{E}=-25.9$

Fig. 6. Selected structures of interacting glycolic acid with ammonium cation corresponding to local minima of energy. Hydrogen bonding interactions characterized by hydrogen - acceptor (HA) and donor - acceptor (DA) distances (in $\AA$ ) as well as an angle donor - hydrogen - acceptor ( $\angle$ DHA, degrees). Relative energy of the system $\Delta E$ corresponds to the relative binding energy, while Inter. $E$ stands for interaction energy calculated without counterpoise correction, both values in $[\mathrm{kcal} / \mathrm{mol}]$

Interestingly, the interaction between ammonium cation and the acid favors strongly by $10 \mathrm{kcal} / \mathrm{mol}$ such a conformation of the acid in which the carbonyl oxygen eclipses $\alpha$-OH, with respect to the conformation in which both the $\mathrm{OH}$ groups are at the same side of the acid. This is much different from the situation in the isolated glycolic acid in which these two conformations were of very similar energy [22],

\subsubsection{Glycolic acid and methylamine cation}

Table 5 presents energies characterizing associates of glycolic acid and protonated methylamine cation. The lowest energy structure corresponds to the strongest interaction between the acid and the amine. The strongest hydrogen bond is formed between $\mathrm{NH}$ and carbonyl oxygen ( $\mathrm{H}$ A distance of $1.700 \AA$ ). The secondary interaction is formed between another amine hydrogen and oxygen atom of $\alpha-\mathrm{OH}$ ( $\mathrm{H} \mathrm{A}$ distance of $2.294 \AA$ ). The weakest 
interaction may be observed between the amine hydrogen engaged in the strongest intermolecular bonding and a-OH (H A distance of $2.599 \AA$ A ) (see Fig. 7).

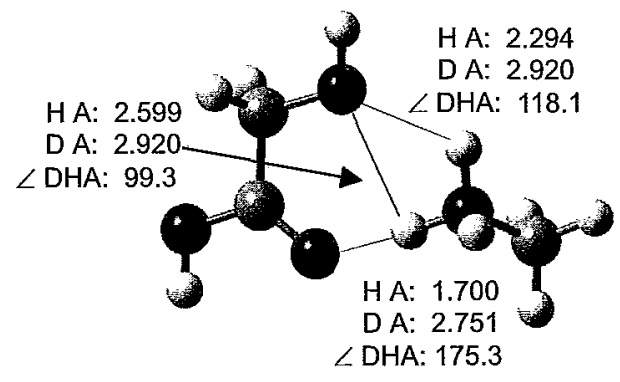

A: $\Delta E=0.0$ Inter. $E=-31.7$

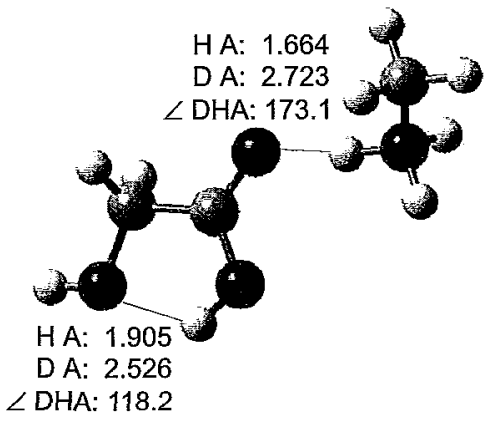

$\mathrm{D}: \Delta \mathrm{E}=0.7$ Inter. $\mathrm{E}=-29.3$

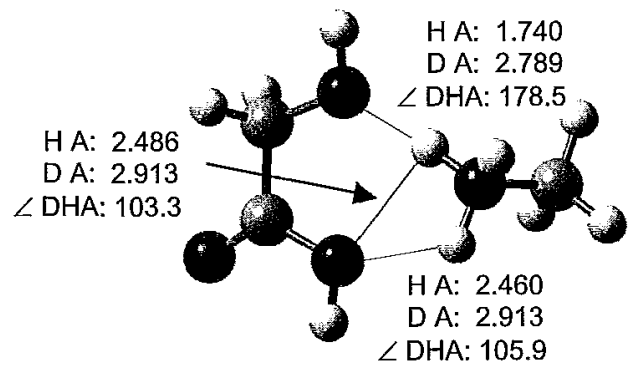

A1: $\Delta E=8.7$ Inter. $E=-22.7$

Fig. 7. Selected structures of interacting glycolic acid with protonated methylamine cation corresponding to local minima of energy. Hydrogen bonding interactions characterized by hydrogen - acceptor (HA) and donor - acceptor (DA) distances (in $\AA$ ) as well as an angle donor - hydrogen - acceptor ( $\angle D H A$, degrees). Relative energy of the system $\Delta \mathrm{E}$ corresponds to the relative binding energy, while Inter.E stands for interaction energy calculated without counterpoise correction, both values in [kcal/mol]

Table 5. Relative energies (in $\mathrm{kcal} / \mathrm{mol}$ ) of the interacting molecules of glycolic acid and protonated methylamine cation in vacuo: binding energy, deformation energy of the acid and the cation, as well as interaction energy of the acid and the cation for various structures of the interacting molecules

\begin{tabular}{cccccc}
\hline \multirow{2}{*}{ Structure } & $\begin{array}{c}\text { Relative } \\
\text { Binding Energy }\end{array}$ & \multicolumn{2}{c}{ Relative Deformation Energy } & \multicolumn{2}{c}{ Interaction Energy } \\
\cline { 2 - 6 } & Complex & Acid & Ammonia & CP & \\
\hline A & 0.0 & 1.8 & 0.2 & -30.9 & -31.7 \\
D & 0.7 & 0.0 & 0.3 & -28.7 & -29.3 \\
A1 & 8.7 & 1.7 & 0.0 & -21.7 & -22.7 \\
\hline
\end{tabular}

$\mathrm{CP}_{\text {counterpoise corrected }}$

Similarly as in the glycolic acid interacting with ammonium cation, the interaction of the amine to the acid when the acid is in a conformation in which carbonyl oxygen and $\alpha-\mathrm{OH}$ 
are at the same side of the molecule is of almost $10 \mathrm{kcal} / \mathrm{mol}$ more favored then the interaction with the acid in the other conformation in which carboxylic $\mathrm{OH}$ and $\alpha-\mathrm{OH}$ are at the same side of the acid.

\subsubsection{Glycolate and ammonia}

Table 6 presents relative energies of the interacting glycolate anion and ammonia. The two lowest energy structures are almost of the same energy: the $\mathbf{D}$ structure is of the lowest energy

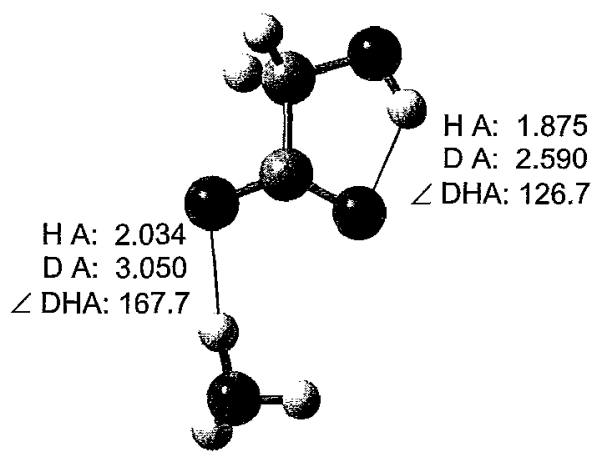

D: $\Delta \mathrm{E}=0.0$ inter. $\mathrm{E}=-9.5$

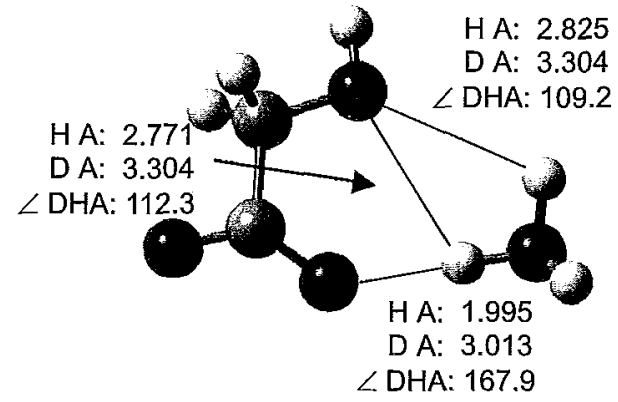

C: $\Delta E=14.5$ Inter $. E=-10.0$

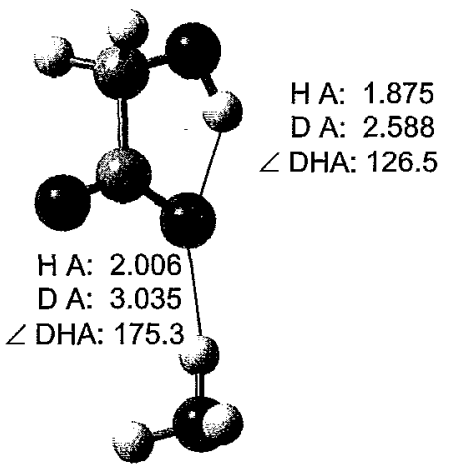

$B: \Delta E=0.3$ Inter. $E=-9.1$

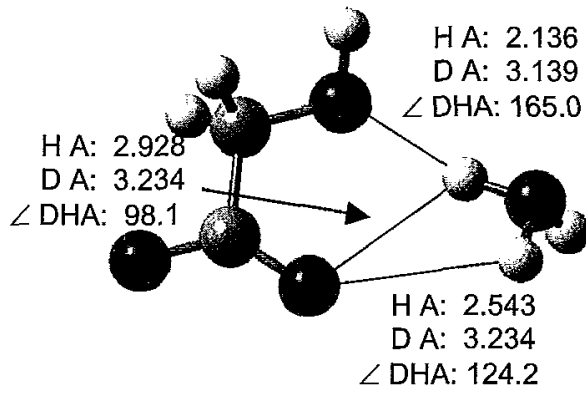

A1: $\Delta E=15.1$ Inter. $E=-9.6$

Fig. 8. Selected structures of interacting glycolate anion with ammonia corresponding to local minima of energy. Hydrogen bonding interactions characterized by hydrogen - acceptor (HA) and donor - acceptor (DA) distances (in $\AA$ ) as well as angle donor - hydrogen - acceptor ( $\angle$ DHA, degrees). Relative energy of the system $\Delta E$ corresponds to the relative binding energy, while Inter. $E$ stands for interaction energy calculated without counterpoise correction, both values in $[\mathrm{kcal} / \mathrm{mol}]$

but the $\mathbf{B}$ one closely follows with the relative energy of $0.3 \mathrm{kcal} / \mathrm{mol}$. In these two structures the glycolate forms intramolecular hydrogen bonding interaction with $\alpha-\mathrm{OH}$ as a donor and carboxylate oxygen as an acceptor (see Fig. 8). In the D structure the intermolecular interaction from $\mathrm{NH}$ of ammonia leads to the oxygen atom of the carboxylate that is not involved in the intramolecular hydrogen bond. As an acceptor in this intermolecular 
Table 6. Relative energies (in $\mathrm{kcal} / \mathrm{mol}$ ) of the interacting molecules of glycolate anion and ammonia in vacuo: binding energy, deformation energy of the acid and ammonia, as well as interaction energy of the acid and ammonia for various structures of the interacting molecules

\begin{tabular}{cccccc}
\hline \multirow{2}{*}{ Structure } & $\begin{array}{c}\text { Relative binding } \\
\text { energy }\end{array}$ & \multicolumn{2}{c}{ Relative deformation energy } & \multicolumn{2}{c}{ Interaction energy } \\
\cline { 2 - 6 } & Complex & Acid & Ammonia & CP & \\
\hline D & 0.0 & 0.0 & 0.1 & -9.0 & -9.5 \\
B & 0.3 & 0.0 & 0.0 & -8.6 & -9.1 \\
C & 14.5 & 15.1 & 0.0 & -9.4 & -10.0 \\
A & 15.1 & 15.2 & 0.1 & -8.7 & -9.6 \\
\hline
\end{tabular}

counterpoise

corrected

hydrogen bond, in the B structure, acts the oxygen atom of the carboxylate that is already involved in the intramolecular interaction.

\subsubsection{Glycolate and methylamine}

Table 7 shows interaction energies, relative binding and deformation energies of various modes of interaction between glycolate anion and methylamine. Similar to the ammonia, for

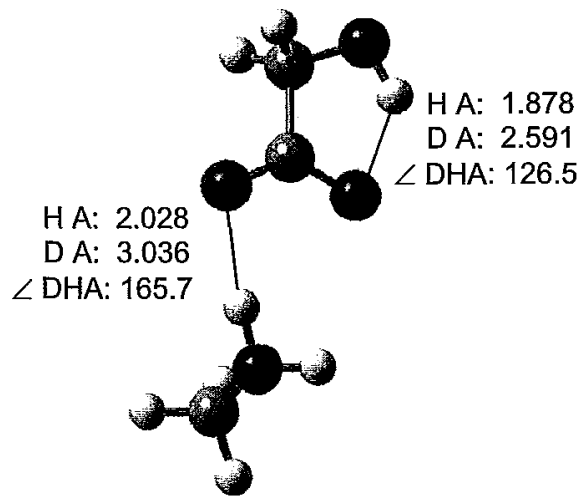

$\mathrm{D}: \Delta \mathrm{E}=0.0$ Inter. $\mathrm{E}=-99$

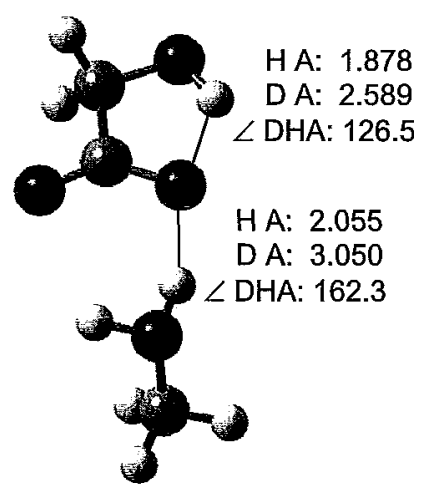

B: $\Delta E=0.1$ Inter. $E=-9.9$

Fig. 9. Selected structures of interacting glycolate anion with ammonia corresponding to local minima of energy. Hydrogen bonding interactions characterized by hydrogen - acceptor (HA) and donor - acceptor (DA) distances (in $\AA$ ) as well as an angle donor - hydrogen - acceptor ( $\angle \mathrm{DHA}$, degrees). Relative energy of the system $\Delta E$ corresponds to the relative binding energy, while Inter. $E$ stands for interaction energy calculated without counterpoise correction, both values in [ $\mathrm{kcal} / \mathrm{mol}]$

methylamine two very similar modes of interaction are favored. The energy difference between them is marginal $(0.1 \mathrm{kcal} / \mathrm{mol})$. In the lowest energy the $\mathbf{D}$ form the hydrogen bond is formed between the $\mathrm{NH}$ group and the oxygen atom not involved in intramolecular inter- 
Table 7. Relative energies of the interacting molecules of glycolate anion and methylamine in vacuo: binding energy, deformation energy of the acid and ammonia, as well as interaction energy of the acid and ammonia for various structures of the interacting molecules

\begin{tabular}{|c|c|c|c|c|c|}
\hline \multirow[b]{2}{*}{ Structure } & \multirow{2}{*}{$\begin{array}{c}\text { Relative } \\
\text { Binding Energy } \\
\text { Complex }\end{array}$} & \multicolumn{2}{|c|}{ Relative Deformation Energy } & \multirow{2}{*}{\multicolumn{2}{|c|}{$\begin{array}{l}\text { Interaction Energy } \\
\text { СР }\end{array}$}} \\
\hline & & Acid & Ammonia & & \\
\hline $\mathrm{D}$ & 0.0 & 0.0 & 0.1 & -9.5 & -9.9 \\
\hline B & 0.1 & 0.0 & 0.2 & -9.4 & -9.9 \\
\hline $\mathrm{C}$ & 14.4 & 15.0 & 0.0 & -9.9 & -10.5 \\
\hline $\mathrm{A} 2$ & 15.1 & 15.1 & 0.4 & -9.4 & -10.2 \\
\hline
\end{tabular}

${ }^{\mathrm{CP}}$ counterpoise corrected

action from $\alpha-\mathrm{OH}$. In the $\mathrm{B}$ structure the other carboxylic oxygen serves as the acceptor of the intermolecular hydrogen bond atom (see Fig. 9).

\subsubsection{CSD search for the relevant hydrogen-bonded ring motifs}

The various modes of interactions of ammonium cation with either $\alpha$-hydroxycarboxyl or carboxyl groups, observed in the crystals of heterochiral salts and resulting from quantum chemical calculations, has prompted us to analyse the population of thus obtained hydrogenbonded ring motifs in nearly 300000 crystal structures deposited in the Cambridge Structural Data Base (CSD, version 5.24, July 2003) [21], We have found 116 supramolecular motifs ${ }^{1}$ containing carboxylate groups joined together by three-center hydrogen bond from the $\mathrm{NH}$ group (no charges specified). Distribution of NH...0 distances (Fig. 10a) clearly shows that the two H... O hydrogen bonds are rarely equal in length, in other words, the three center hydrogen bond usually has its major and minor component.

Population of the three center bonds formed by $\mathrm{NH}$ group and two oxygens from the $\mathrm{O}-\mathrm{C}-\mathrm{C}-\mathrm{O}$ fragment is much higher and equals to 272. As can be seen from Fig. $10 \mathrm{~b}$, which is the scattegram of the two NH...0 distances, in many cases the two NH...0 bonds differ in length. Shorter bonds dominate among those formed with carboxylate oxygens. High population of this type of hydrogen bond motifs might be an indication that in the process of molecular recognition the amine approaches tartaric acid molecule from the $\alpha$-hydroxycarboxylate bay region. Depending on the complementarity of the two interacting moieties, the amine either joins by hydrogen bonds the whole $\alpha$-hydroxycarboxylate moiety or evolves towards formation of hydrogen bonds which involve, exclusively, either hydroxyl or carboxyl group.

Stimulated by quantum chemical calculations we have also examined in the CSD the population of motifs that involve both $\mathrm{N}-\mathrm{H}$ bonds to join together two oxygen atoms

\footnotetext{
${ }^{1}$ Multiple entries in the CSD were not removed
} 
a)
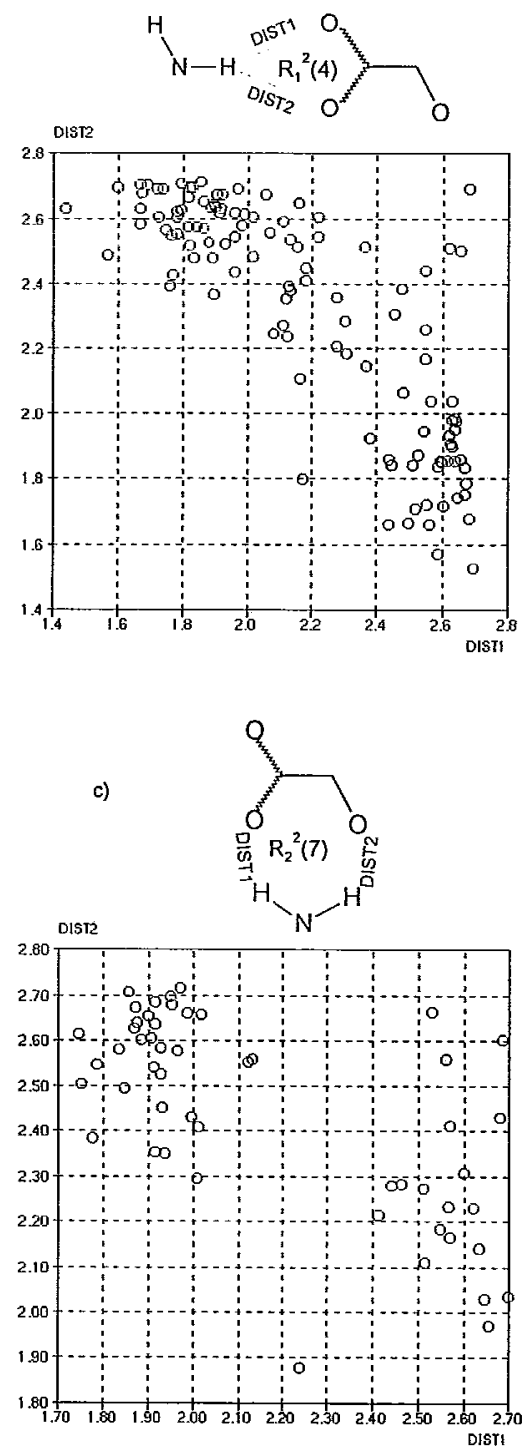

b)
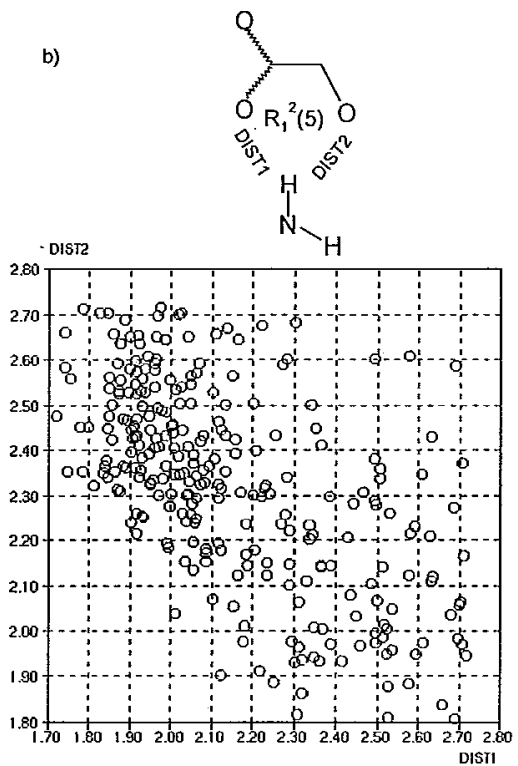

d)
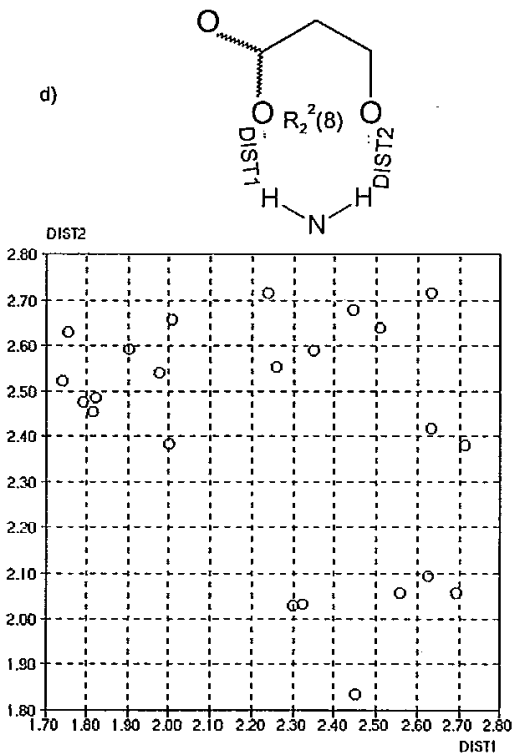

Fig. 10. Scatter plots showing the distribution of two NH...0 distances in hydrogen-bonded ring associations involving acyclic amine as donor and acyclic carboxylate or $\alpha$-hydroxcarboxylate as hydrogen bond acceptor site. Wavy lines stand for unspecified bond type: a) $\mathrm{NH} / 0_{2} \mathrm{C}$ system, 116 observations; b) NH/O-C-C-O system, 272 observations; c) $\mathrm{NH}_{2} / 0-\mathrm{C}-\mathrm{C}-0$ system, 52 observations; d) $\mathrm{NH}_{2} / \mathrm{O}-\mathrm{C}-\mathrm{C}-\mathrm{C}-\mathrm{O}$ system, 20 observations 
situated in either $\alpha$ or $\beta$ position with respect to each other (the $R_{2}^{2}(1)$ and $R_{2}^{2}(8)$ motifs, respectively). As can be seen from Fig $10 \mathrm{c}$ and $\mathrm{d}$ such motifs are by far less common in crystals (total observations 52 and 23, respectively). Again, there is a clear bias in the distribution of $\mathrm{NH} \ldots 0$ bond lengths. Short bonds more often appear among the hydrogen bonds to carboxylate oxygens than to hydroxy 1 oxygens.

We may conclude the CSD search by stating that in crystals, the probability of formation by the $\mathrm{NH}_{2}$ group of bimolecular hydrogen bonded ring motifs via only one $\mathrm{NH}$ donor (the so called three center bond) is much higher than the probability of formation of ring motifs involving two separate $\mathrm{NH} \ldots 0$ bonds. The hydrogen atom not involved in the formation of the cycle is most likely utilized in expanding this motif further in a crystal. In vacuo, the preference for cyclic motifs involving both hydrogen atoms from the amine group is well understood owing to the fact that the most energetically preferred are those arrangements which tend to exploit all available hydrogen bonding sites.

\section{CONCLUSIONS}

According to the quantum mechanical calculations the minimum energy structure for which a potential chiral recognition between amine or protonated amine and $\alpha$-hydroxycarboxylic acid can take place is the one that involves the protonated chiral amine and protonated acid. This suggests, that the possible resolving agents for the protonated chiral amines might be found among esters of $\alpha$-hydroxycarboxylic acids. Thus it is tempting to assume that the ring motif utilizing protonated amine as a donor of two hydrogen bonds aiming at carbonyl oxygen and $\alpha$-hydroxyl oxygen atoms could be a model for recognition and enentioselective binding of chiral $\alpha$-hydroxyesters with racemic amines. However, the results from CSD indicate that the $R_{2}{ }^{2}(7)$ and $R_{2}{ }^{2}(6)$ ring motifs utilizing two NH bonds are less common then the $R_{1}^{2}(5)$ and $R_{1}{ }^{2}(4)$ ring motifs utilizing only one $\mathrm{NH}$ three-center hydrogen bond. On the other hand, the $R_{1}{ }^{2}(5)$ and $R_{2}{ }^{2}(7)$ motifs appeared simultaneously in quantum mechanical in vacuo calculations and only their relative strength varied. All in all these motifs seem to be very promising targets for molecular and possibly chiral recognition.

\section{Acknowledgement}

This scientific work was financed by Polish Committee for Scientific Research (KBN) from the year 2003 to 2006 as the research project - grant number 4T09A18525. Authors thank Poznan Supercomputing and Networking Center for the access to the resources therein. M.H. gratefully acknowledge the support from the Foundation for Polish Science grant for fellows number 6/03.

\section{References}

[1] U. Rychlewska, B. Warżajtis, Acta Cryst., B56, 833 (2000).

[2] A. Szarecka, U. Rychlewska, J. Rychlewski, J. Mol. Struct., 474, 25 (1999).

[3] A. Szarecka, J. Rychlewski, U. Rychlewska, Quantum Systems in Chemistry and Physics, 2, 355 (2000). 
[4] F. Maseras, K. Morokuma, J. Comput. Chem. 16, 1170 (1995).

[5] M. Svensson, S. Humbel, R.D.J. Froese, T. Matsubara, S. Sieber, K. Morokuma, J. Phys. Chem. 100, 19357(1996).

[6] S. Dapprich, I. Komarami, K. S. Byun, K. Morokuma, M. J. Frisch, J. Mol. Struct. Theochem, 1, 461 (1999).

[7] T. Vreven, K. Morokuma, J. Comput. Chem. 16, 1419 (2000).

[8] Gaussian 03, M. J. Frisch, G. W. Trucks, H. B. Schlegel, G. E. Scuseria, M. A. Robb, J. R. Cheeseman, J. A. Montgomery, Jr., T. Vreven, K. N. Kudin, J. C. Burant, J. M. Millam, S. S. Iyengar, J. Tomasi, V. Barone, B. Mennucci, M. Cossi, G. Scalmani, N. Rega, G. A. Petersson, H. Nakatsuji, M. Hada, M. Ehara, K. Toyota, R. Fukuda, J. Hasegawa, M. Ishida, T. Nakajima, Y. Honda, O. Kitao, H. Nakai, M. Kiene, X. Li, J. E. Knox, H. P. Hratchian, J. B. Cross, C. Adamo, J. Jaramillo, R. Gomperts, R. E. Stratmann, O. Yazyev, A. J. Austin, R. Cammi, C. Pomelli, J. W. Ochterski, P. Y. Ayala, K. Morokuma, G. A. Voth, P. Salvador, J. J. Dannenberg, V. G. Zakrzewski, S. Dapprich, A. D. Daniels, M. C. Strain, O. Farkas, D. K. Malick, A. D. Rabuck, K. Raghavachari, J. B. Foresman, J. V. Ortiz, Q. Cui, A. G. Baboul, S. Clifford, J. Cioslowski, B. B. Stefanov, G. Liu, A. Liashenko, P. Piskorz, I. Komaromi, R. L. Martin, D. J. Fox, T. Keith, M. A. Al-Laham, C. Y. Peng, A. Nanayakkara, M. Challacombe, P. M. W. Gill, B. Johnson, W. Chen, M. W. Wong, C. Gonzalez, and J. A. Pople, Gaussian, Inc., Pittsburgh PA, (2001).

[9] J. Gawroński, K. Gawrońska, Tartaric and Malic Acids in Synthesis, John Wiley \& Sons, Inc., New York, NY, USA (1999).

[10] J. Gawroński, private communication.

[11] S. Hanessian, M. Simard, S. Roelens, J. Am. Chem. Soc. 117, 7630 (1995).

[12] U. Rychlewska, J. Mol. Struct., 474, 235 (1999).

[13] O. Ermer, A. Eling, J. Chem. Soc. Perkin Trans. 2, 925 (1994).

[14] S. Hanessian A. Gomtsyan, M. Simard, S. Roelens J. Am. Chem. Soc. 116, 4495 (1994).

[15] S. Hanessian R. Saladino, R. Margarita, M. Simard, Chem. Eur. J. 5, 2169 (1999).

[16] S. Roelens, P. Dapporto, P. Paoli, Can. J. Chem. 78, 723 (2000).

[17] P. Dapporto, P. Paoli, S. Roelens, J. Org. Chem. 66, 4930 (2001).

[18] J. Bernstein, R. E. Davis, L. Shimoni, N. L. Chang, Angevv. Chem. Int. Ed. Engl, 34, 1555 (1995).

[19] Y. Okaya, N. R. Stemple, M. I. Kay, Acta Cryst. 21, 237 (1966).

[20] U. Rychlewska, A. Szarecka, J. Rychlewski, R. Motala, Acta Cryst., B55, 617 (1999).

[21] F. H. Allen, O. Kennard, Chem. Des. Automat. News., 8(1), 31 (1993).

[22] M. Hoffmann, A. Szarecka. J. Rychlewski, Adv. Quant. Chem., 32, 109 (1999). 